\title{
Prediction of Runaway Characteristics of Kaplan Turbines Using CFD Analysis
}

\author{
A. V. Semenova ${ }^{1 *}, D . V$. Chirkov $^{2}$ and $A . S$. Ustimenko ${ }^{1}$ \\ ${ }^{1}$ JSC Power Machines Saint Petersburg, Russia \\ ${ }^{2}$ Institute of Computational Technologies SB RAS, Novosibirsk, Russia
}

\begin{abstract}
In case of disconnection of generator from the network and failure of the governor, the rotational speed of the rotor rapidly increases and achieves maximum value, called the runaway speed. Prediction of the runaway speed at the stage of runner design would allow to select a runner considering this characteristic. Given in this paper is the numerical prediction of the runaway speed for a Kaplan turbine. Two approaches for numerical simulation were discussed. In the first one, the flow in the turbine flow passage was simulated using 3-D RANS equations of incompressible fluid using $\mathrm{k}-\varepsilon$ turbulence model. In the second approach, cavitation phenomena were taken into account using two-phase Zwart-Gerber-Belamri (ZGB) cavitation model. CFD calculations were carried out with using CADRUN flow solver. When setting the boundary conditions, the turbine head, being the difference of energies in the inlet and outlet cross-sections, is pre-set as a constant value, while the discharge and the runner torque are determined in the process of computation. The computed runaway speed is compared to that obtained in the model tests. It is shown that the numerical prediction of the runaway speed using the cavitation model achieves better matching with the experimental data.
\end{abstract}

\section{Introduction}

The runaway speed is the maximum runner speed that is achieved in case of emergency disconnection of the generator from the network and governor failure or broken distributor. Achieving the runaway speed is dangerous for the hydro-unit, especially for the generator rotor. Knowledge of this value is required for stress analysis of the components of the runner and other rotating parts connected with the shaft, stress analysis of the generator rotor, and calculation of the critical speed of the unit shaft rotation. At present the runaway characteristics, (runaway speed vs. turbine operating point) is obtained at the stage of model tests. Prediction of the runaway speed at the stage of runner design would allow to select a runner considering this characteristic and to guarantee fulfilment of the contract requirements. Given in the present paper is the method for CFD calculation of the runaway characteristics of the Kaplan turbine carried out using CADRUN flow solver developed in

* Corresponding author: semenova av@power-m.ru 
Institute of Computational Technologies and Institute of Mathematics of Siberian Branch of Russian Academy of Sciences in collaboration with Power Machines.

\section{Problem setup and computational approach}

The runaway speed depends on the turbine type, operating condition, the shape of the flow passage and runner blade system. The values of the runaway speed for different operating conditions of the turbine are determined via special runaway speed model tests in course of which the model is brought to runaway with different positions of guide vanes and runner blades. Since during the runaway the prototype turbine might get into cavitation condition, a constant value of the Thoma number (corresponding to the worst cavitation conditions at the power plant) is being maintained in the course of the model tests. The obtained values of the runaway speed are scaled up to the unit turbine $\left(D_{1}=1 \mathrm{~m}, H=1 \mathrm{~m}\right)$. The runaway speed of the prototype turbine $n_{\mathrm{R}}$ is then calculated using corresponding unit runaway speed $n_{11 \mathrm{R}}$ in accordance with the following formula:

$$
n_{R}=n_{11 R} \frac{\sqrt{H_{\max }}}{D_{1}},
$$

where: $n_{l 1 R}$ is unit runaway speed [rpm]; $H_{\max }$ is the maximum turbine head, $[\mathrm{m}] ; D_{1}$ is the prototype runner diameter $[\mathrm{m}]$.

Two cases are possible when a Kaplan turbine is in the runaway condition. In the first case, failure of the governor makes it loose its ability to control the motion of the guide vanes and runner blades, and the relationship between the guide vane opening (GVO) and runner blade angle is broken. For this case, it is necessary to determine the greatest runaway speed value of all possible combinations of guide vane opening and runner blade angle (off-cam condition). As a rule, this value is achieved at small runner blade angle and high GVO. In the second case of governor failure, the GVO/runner blade angle relationship (on-cam condition) is maintained, i.e. the runner blade angle depends on the GVO. In this case, runaway speed is less than in the first case since for small runner blade angle the guide vane opening is also small.

In order to numerically obtain the value of runaway speed for the given GVO and runner blade angle a set of flow calculations for different rotation speed were carried out and the speed at which the torque on the shaft is equal to zero, was determined. Evaluation of runaway speeds for operating points with different guide vane and runner blade positions allows to draw the runaway curve. In the present paper numerical calculations were carried out for several runner blade angles. For each runner blade angle a set of guide vane openings were computed. Thus, the off-cam condition (the worst case) is considered.

We considered two CFD approaches for prediction of runaway characteristics. In the first approach, the flow in the turbine was simulated using 3D steady-state incompressible RANS equations with $k-\varepsilon$ turbulence model. In the second approach cavitation phenomena were simulated using homogeneous "liquid-vapor" mixture model [1]. As such a model Favre averaged Navier-Stokes equations governing the motion of isothermal compressible mixture are used. Zwart-Gerber-Belamri (ZGB) model is applied for vaporization and condensation terms in transport equation of liquid volume fraction [2].

In both cases, the combined method of calculation of energy losses was used [3]. The idea of the combined method is that energy losses in the main components of the flow passage are calculated directly using CFD, whereas energy losses in the remaining parts of the flow passage are calculated using simple empirical formulas without CFD computation. In this paper the losses in the spiral case and stay ring are calculated using empirical formulas, while 
the losses in the distributor, the runner and the draft tube are calculated using CFD analysis. One of the particularities of Kaplan turbines is the presence of clearances between the runner blade and the hub, and between the runner blade and the chamber. These clearances affect considerably the runner and draft tube performance as well as cavitation characteristics of the runner. Therefore, it is necessary to account the clearances in CFD analysis.

\section{Boundary conditions}

In general, hydro-dynamic calculations of the flow in the water passages are carried out at fixed GVO, runner blade angle, and full head of the turbine. A priory, the discharge is not known and is determined in the course of solution. Such an approach was used by the authors for simulation of the single-phase incompressible and two-phase cavitating flows in turbine flow passages $[1,4,5,6]$. In the inlet of the distributor total flow energy $E_{\text {in }}$ (equivalent to total pressure) and flow angle are kept constant.

$$
E_{\text {in }}=E_{\text {out }}+H-h_{s p},
$$

where: $h_{S P}$ is the energy loss in the spiral case and stay ring evaluated a-priory in accordance with empirical formulas [m]; $H$ is the total turbine head [m]; $E_{\text {out }}$ is the flow energy in the draft tube outlet cross-section [m].

In case of calculation without considering cavitation phenomena, $E_{\text {out }}$ can be set to zero:

$$
E_{\text {out }}=0 \text {. }
$$

In case of calculation with cavitation taken into account, $E_{\text {out }}$ is evaluated in accordance to IEC standard 60193 [7] for Kaplan turbines:

$$
E_{\text {out }}=\sigma H+\frac{p_{v}}{\rho g},
$$

where: $p_{v}$ is the saturated vapor pressure $[\mathrm{Pa}], \sigma$ is the Thoma number.

Thus, with a pre-set value of $\sigma$ and known head $H$, the energy $E_{\text {out }}$ in the outlet crosssection is fixed, whereas discharge and pressure of the fluid are not known as separate values and determined during the process of solution. The pressure at the inlet boundary is extrapolated from the inside of the computational domain, while all velocity components are extrapolated from the inside at the draft tube outlet boundary.

\section{Results}

CFD calculations were carried out for a turbine designed for $H=40 \mathrm{~m}$ with number of runner blades $z_{1}=6$. The calculations were carried out for the conditions of the scale model turbine: $D_{1}=0.46 \mathrm{~m}, H=3.4 \mathrm{~m}$. In case of cavitational calculations Thoma number $\sigma=0.6091$ (corresponding to the worst power plant cavitation conditions if the turbine falls into runaway) was pre-set in (4). Gravity $g=9.81 \mathrm{~m} / \mathrm{s}^{2}$ was taken into account in all calculations. The calculations were carried out for three runner blade angles $f_{\mathrm{i}}=-5^{\circ}, 0^{\circ}$ and $5^{\circ}$ and several guide vane openings $a_{0}=36 \mathrm{~mm}, 40 \mathrm{~mm}, 44 \mathrm{~mm}, 48 \mathrm{~mm}, 52 \mathrm{~mm}$. During the model tests, maximum runaway speed was achieved at $\mathrm{a}_{0}<52 \mathrm{~mm}$. Relationships between the model rotational speed and discharge through the model turbine and their respective unit values were determined using the following formulas: 


$$
n_{11}=\frac{n D_{1}}{\sqrt{H}} ; Q_{11}=\frac{Q}{D_{1}^{2} \sqrt{H}},
$$

where: $n_{11}$ is the unit rotational speed [rpm]; $n$ is the rotational speed of the model turbine [rpm]; $Q_{11}$ is the unit discharge $\left[\mathrm{m}^{3} / \mathrm{s}\right] ; Q$ is the model discharge $\left[\mathrm{m}^{3} / \mathrm{s}\right] ; D_{1}=0.46 \mathrm{~m}$ is the nominal diameter of the model runner, $H=3.4 \mathrm{~m}$ is the model net head.

To obtain the runaway speed only the hydraulic torque on the turbine runner was calculated using numerical simulation, while the mechanical losses were neglected. For all CFD analyses periodic stage approach was used, which implies that the flow in all guide vane channels and blade-to-blade channels are considered to be identical. Within this approach, steady-state CFD analysis was carried out in the domain including one guide vane channel, one blade-to-blade channel (with clearances), and in the draft tube. Block structured mesh for numerical simulation is presented in figure 1 .

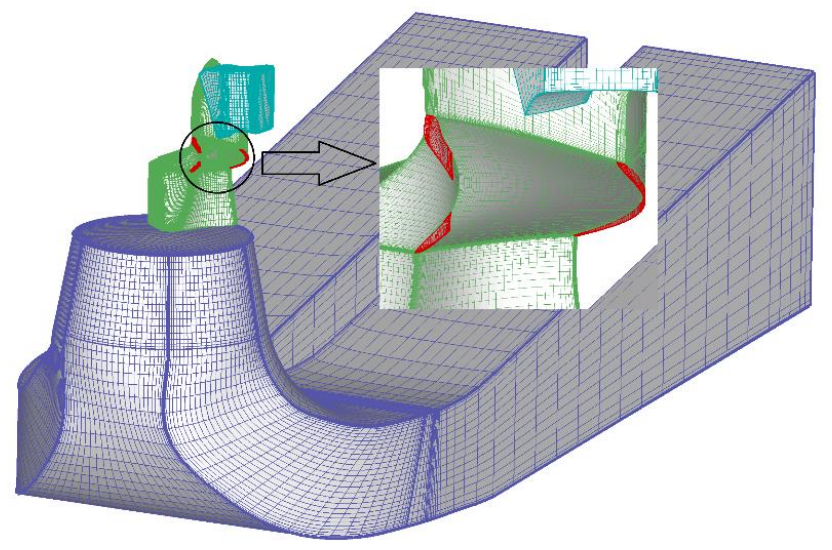

Fig. 1. Computational mesh with hub and blade tip clearances.

As noted above, to obtain the runaway speed a set of steady-state numerical calculations was carried out. Calculations were carried out for given guide vane opening and runner blade angle and different rotation speed values. Runaway speed is the speed at which runner torque is equal to zero. Figures 2 and 3 show the dependencies of the hydraulic torque on unit rotation speed computed without and with cavitation model taken into account, for two positions of GVO. It can be seen from the figures that cavitation phenomena affect the value of runaway speed.

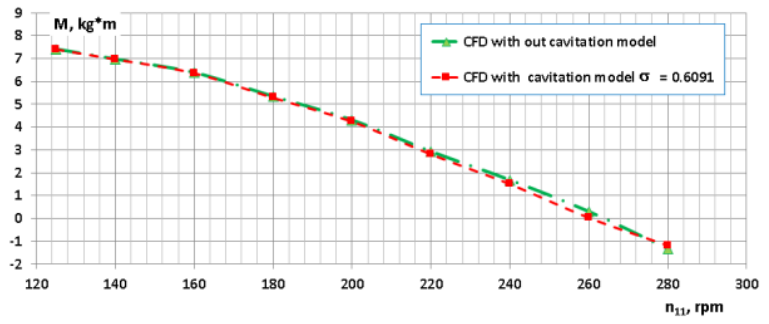

Fig. 2. Hydraulic torque on the model shaft vs unit rotational speed for $f i=0^{\circ}, a_{0}=40 \mathrm{~mm}$. 


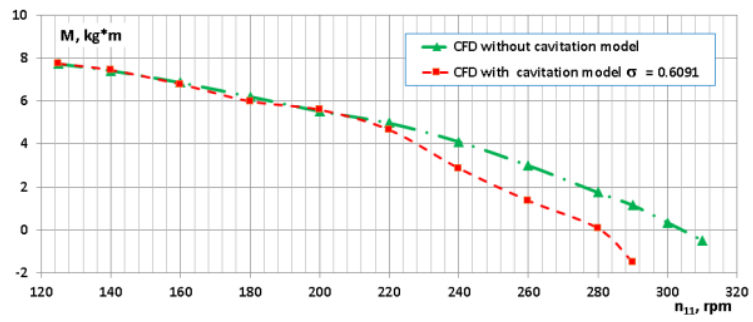

Fig. 3. Hydraulic torque on the model shaft vs unit rotational speed for $f i=0^{\circ}, a_{0}=52 \mathrm{~mm}$.

Figures 4 and 5 show distributions of the volume fraction of liquid phase on the blades and the hub at unit rotation speed $\mathrm{n} 11$ close to runaway speed for two operation points. From figure 4 it is seen that in operation point $\left\{f i=0^{\circ}, a_{0}=40 \mathrm{~mm}\right\}$ cavitation phenomena are observed only on the pressure side of the blade and in a narrow zone near the flange on the suction side. For this operating point single phase incompressible and cavitating flow models give approximately the same value of the runaway speed (figure 2).

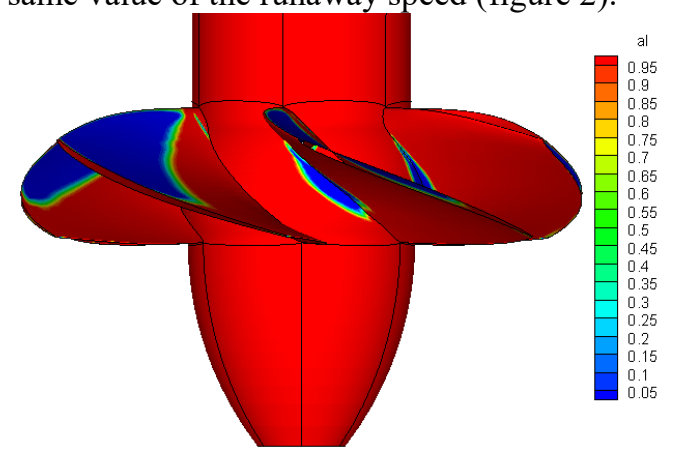

Fig. 4. Distribution of volume fraction of liquid phase on blade and hub $\left(f i=0^{\circ}, a_{0}=40 \mathrm{~mm}, n_{11}=260 \mathrm{rpm}\right)$.

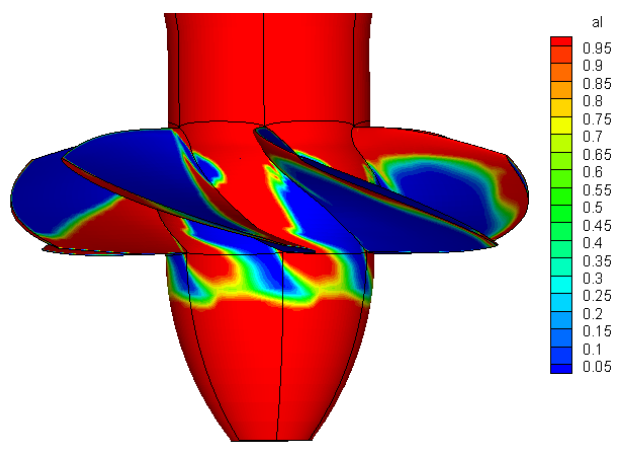

Fig. 5. Distribution of volume fraction of liquid phase on blade and hub $\left(f i=0^{\circ}, a_{0}=52 \mathrm{~mm}, n_{11}=280 \mathrm{rpm}\right)$.

From Figure 5 it is seen that significant cavitation phenomena are observed in the operation point $\left\{f_{i}=0^{\circ}, a_{0}=52 \mathrm{~mm}\right\}$. We can see cavitation zones both on suction and pressure sides of blade. The value of the runaway speed calculated using cavitation model is significantly lower than that calculated without one (figure 3 ).

Given in figures 6-8 the comparison between CFD runaway curves (runaway speed and unit discharge $Q_{11}$ vs guide vane opening $a_{0}$ ) and curves measured experimentally in the Laboratory of Hydraulic Turbines, property of Power Machines. 


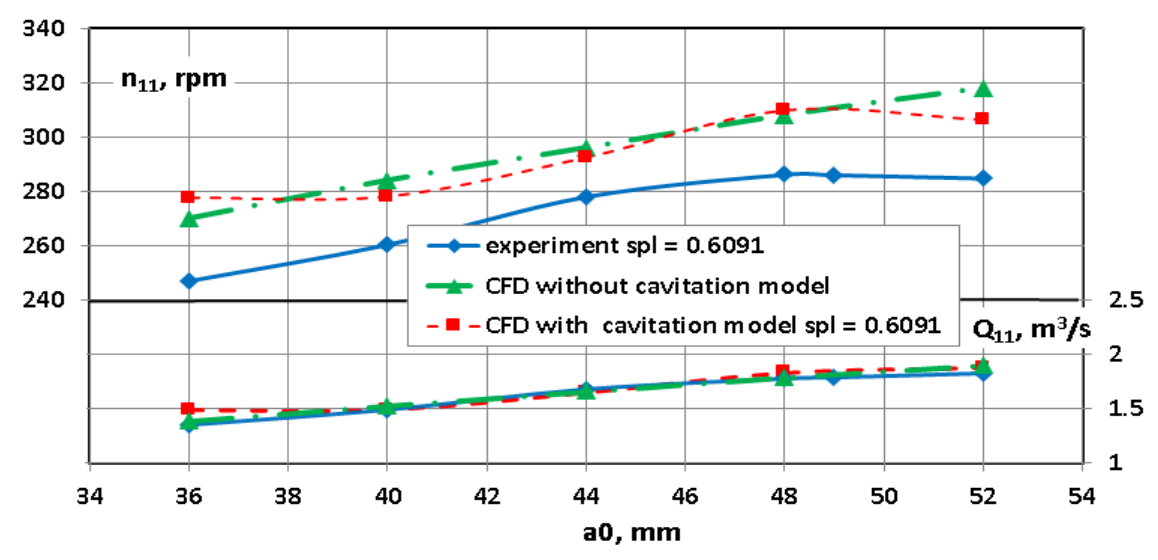

Fig. 6. Runaway speed and discharge vs guide vane opening for $f_{i}=-5^{\circ}$.

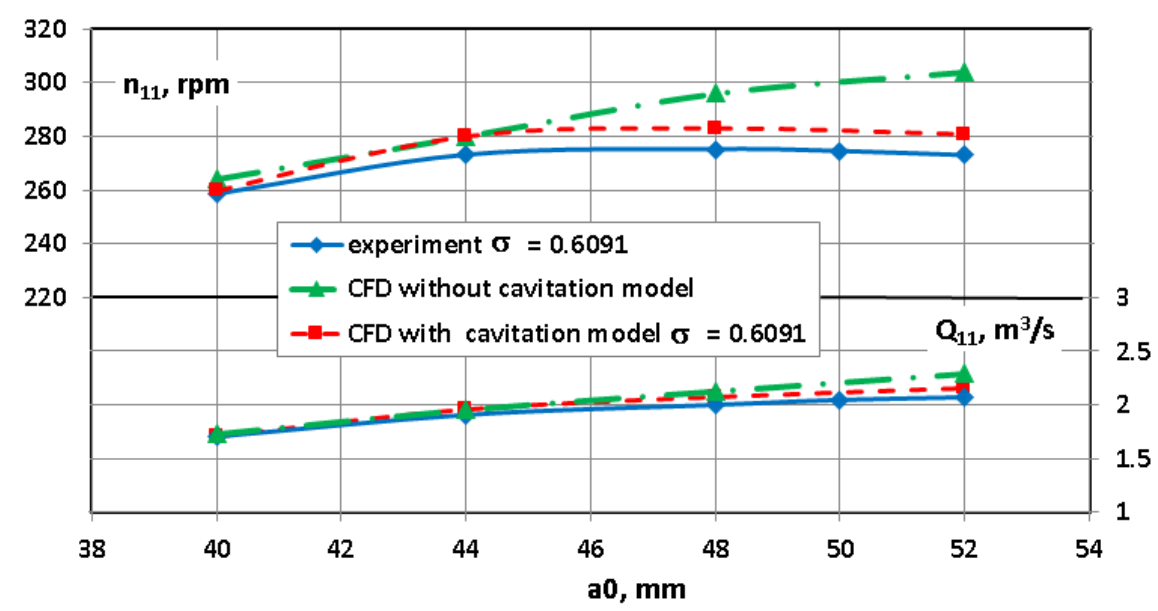

Fig. 7. Runaway speed and discharge vs guide vane opening for $f_{i}=0^{\circ}$.

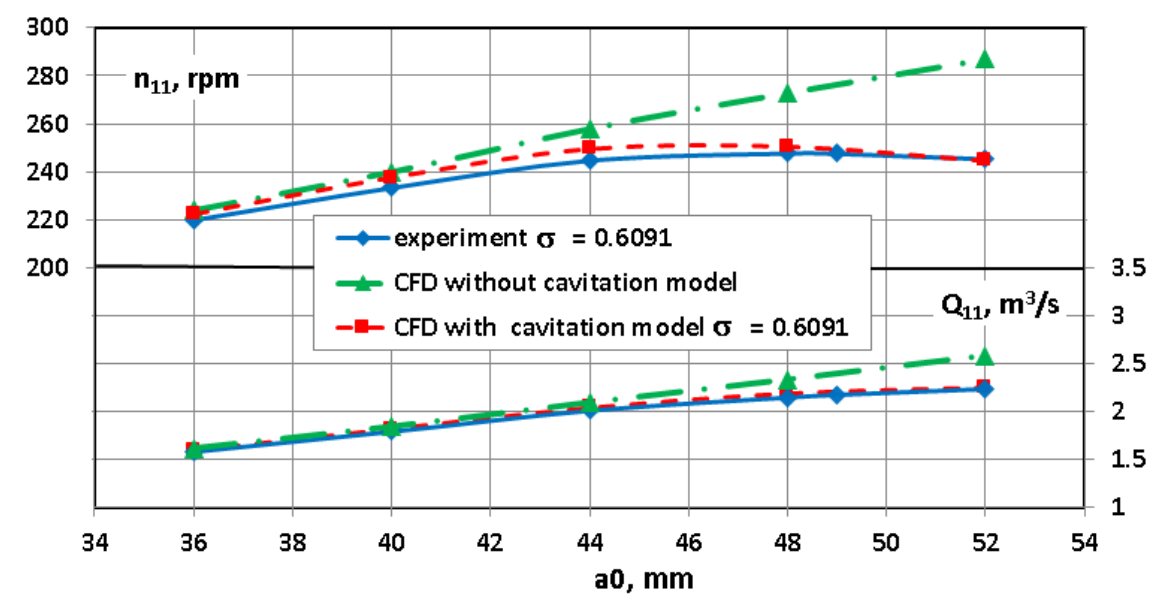

Fig. 8. Runaway speed and discharge vs guide vane opening for $f_{i}=5^{\circ}$. 
It is shown that cavitational calculations better agree to experimental data than incompressible ones.

During the model tests, the influence of the Thoma number on the runaway speed was studied for different runner blade angles. For a given runner blade angle the GVO, providing the maximal runaway speed, is considered. Given in figures 9-11 is the comparison between the curves obtained via experiments and the curves obtained via calculations.

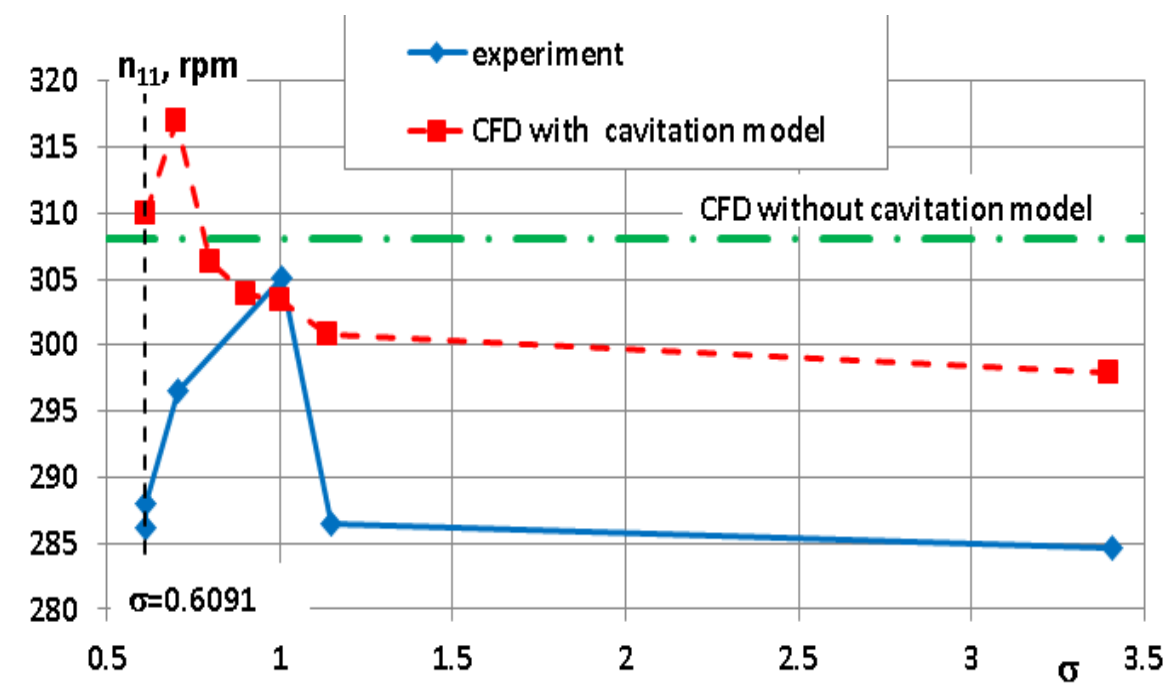

Fig. 9. Runaway speed vs Thoma number for $f_{i}=-5^{\circ}, a_{0}=48 \mathrm{~mm}$.

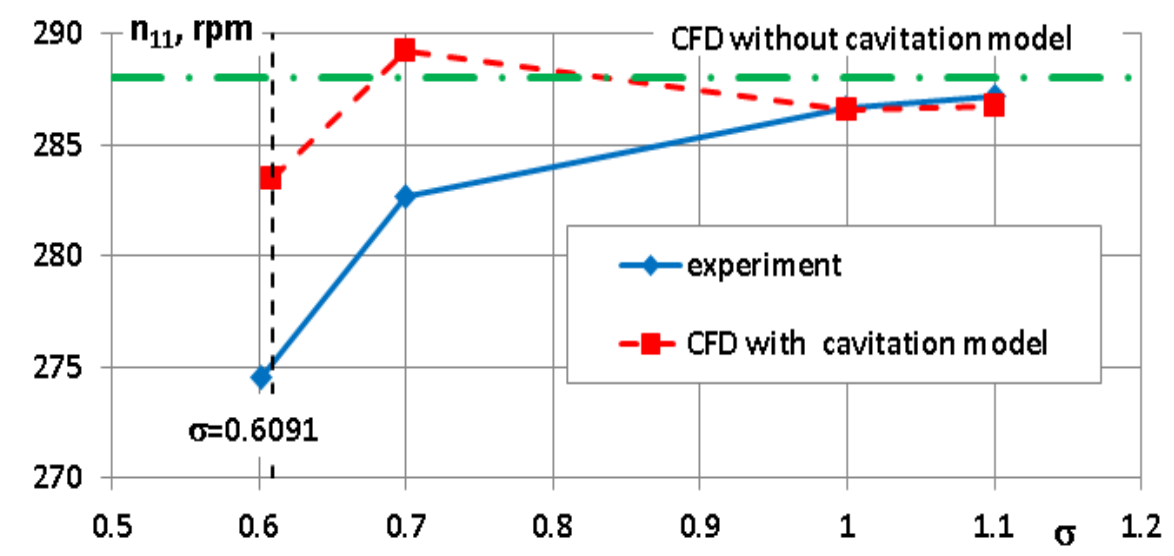

Fig. 10. Runaway speed vs Thoma number for $f_{i}=0^{\circ}, a_{0}=46 \mathrm{~mm}$. 


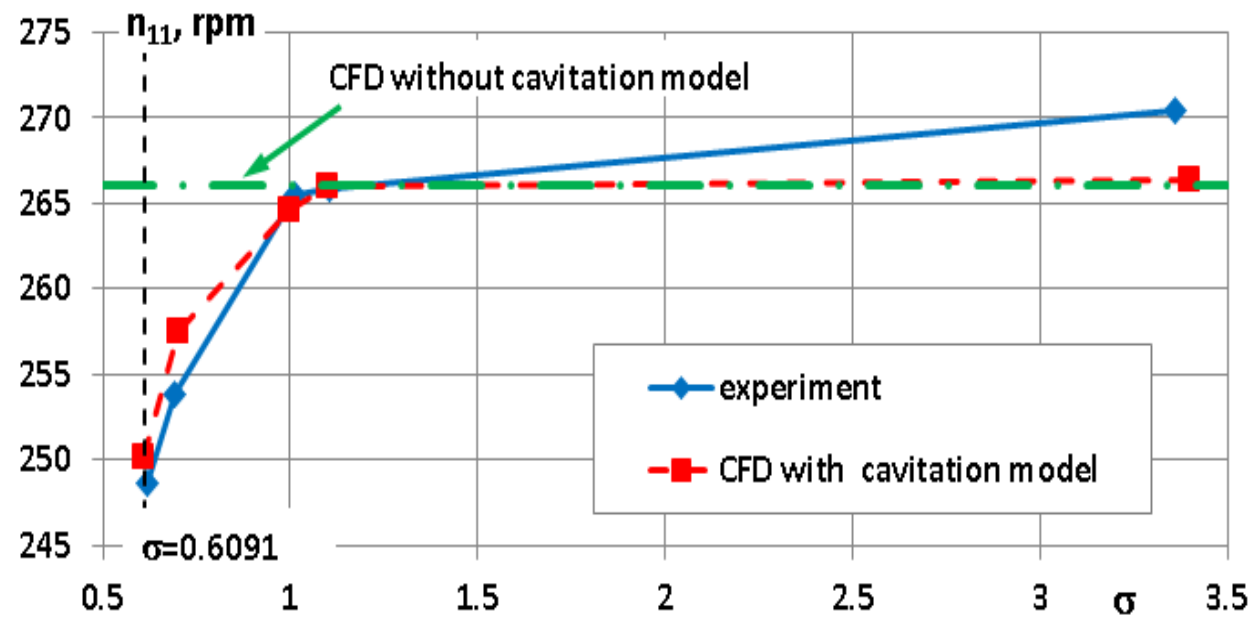

Fig. 11. Runaway speed vs Thoma number for $f_{i}=5^{\circ}, a_{0}=46 \mathrm{~mm}$.

It is seen from the above results that account of cavitation has a considerable influence on the computed runaway speed. Cavitation has also the influence on the discharge through the turbine corresponding to the runaway speed. Hence, these characteristics should be computed using cavitation model.

From figures $6-8$ it is seen that calculations using the selected model of cavitation and statement of boundary conditions give a good agreement to experimental data both in shape of the curves and the values of the runaway speed. The value of the runaway speed is slightly over-predicted, especially for small runner blade angles. This behavior might be explained by neglecting the mechanical losses. The results of calculations presented in figures 9-11 also show a satisfactory coincidence with experimental results.

\section{Conclusion}

Two approaches for predicting the runaway characteristics of Kaplan turbines have been studied. In the first approach, the flow in the turbine is simulated using 3D steady-state incompressible flow model closed by standard k-e turbulence model. In the second approach, the account of cavitation was added using a Zwart-Gerber-Belamri two-phase cavitation model. In both cases constant turbine head $H=$ const was set as a boundary condition, while the discharge through the turbine was determined in the process of solution. It is shown that calculations using the selected model of cavitation give the better agreement to experimental data both in shape of the curves and the values of the runaway speed than incompressible ones. The value of the runaway speed is slightly over-predicted in comparison to experimental data. This behavior might be explained by the fact that only hydraulic torque on the turbine shaft was computed in the present simulations, while the mechanical losses were neglected. The highest discrepancy is observed for the smallest runner blade angle, $f_{i}=-5^{\circ}$. This issue should be investigated further.

Thus, the described CFD approach considering cavitation proved to be promising since it can predict runaway characteristics of the turbine and can be used in the runner design process. 


\section{References}

1. L. V. Panov, Chirkov D. V., Cherny S. G., Pylev I. M. and Sotnikov A. A. Numerical simulation of steady cavitating flow of viscous fluid in a Francis hydroturbine Thermophysics and Aeromechanics 19, 415-27, 2012

2. P. J. Zwart, Gerber A. G. and Belamri T. A. Two-phase flow model for predicting cavitation dynamics. ICMF 2004 International Conference on Multiphase Flow. Paper No. 152 (Yokohama, Japan), 2004

3. A. Sotnikov, Cherny S., Chirkov D. and Bannikov D. Two Approaches to Prediction of Hill Diagram for Francis Turbine. Proceedings of Hydro Vision Russia - 2011, (Moscow, Russia) p. 1-15, 2011

4. A. Semenova, Chirkov D., Lyutov A., Chemy S., Skorospelov V. and Pylev I. Multiobjective shape optimization of runner blade for Kaplan turbine IOP Conference Series: Earth and Environmental Science vol 22 (Institute of Physics Publishing) p 012025, 2014

5. L. V. Panov, Chirkov D. V., Cherny S. G. and Pylev I. M. Numerical simulation of pulsation processes in hydraulic turbine based on 3D model of cavitating flow Thermophysics and Aeromechanics 21, 31-43, 2014

6. M. Sokolova, Semenova A. The design of the Kaplan turbine runner using the method of the cavitation characteristic prediction Hydraulic machines, hydraulic pneumatic actuator and hydraulic and pneumatic control systems. Current state and prospects of development: collection of scientific papers of the international scientific and technical conference. St.Peterburg Polytechnic University p. 176-186, 2018

7. IEC Standard 60193. Hydraulic turbines, storage pumps and pump-turbines. Model acceptance tests IEC: International Electrotechnical Commission, 1999 